$16^{\circ}$ USIHC - Congresso Internacional de Ergonomia e Usabilidade de USIHC Interfaces Humano Computador

\title{
O DESIGN APLICADO NA TECNOLOGIA ASSISTIVA - ESTUDO DE CASO DOS ANDADORES PARA IDOSOS
}

\section{THE DESIGN APPLIED IN ASSISTIVE TECHNOLOGY - CASE STUDY OF THE WALKERS FOR ELDERLY}

\author{
Vanessa Maiara Domingues de Oliveira ${ }^{1}$ \\ João Carlos R. Plácido da Silva², Dr. \\ José Carlos Plácido da Silva ${ }^{3}$, Dr. \\ Luis Carlos Paschoarelli ${ }^{4}$, Dr.
}

(1) Universidade do Sagrado Coração

e-mail: vanessa21oliveira@hotmail.com

(2) Universidade do Sagrado Coração

e-mail: joaocarlos_placido@hotmail.com

\author{
(3) UNESP - FAAC \\ e-mail: placido@ faac.unesp.br \\ (4) UNESP - FAAC \\ e-mail: paschoarelli@ faac.unesp.br
}

Palavras-chave: Andador, idosos, ergonomia.

O presente trabalho tem por objetivo analisar princípios que circundam a projeção de andadores e o bom uso aos idosos com mobilidade reduzida. Foi realizada uma revisão bibliográfica que pondera resultados para novas pesquisas, pois o emprego do material inadequado e a ausência ergonômica e estética são fatores motivadores à desistência do dispositivo.

\section{Key-words: Walker, elderly, ergonomics.}

The present work aims to analyze principles that surround the projection of walkers and the good use to the elderly with reduced mobility. A bibliographical review was carried out to evaluate results for new research, since the use of inappropriate material and the absence of ergonomic and aesthetic are motivating factors for the device's withdrawal. 


\section{$16^{\circ}$ \\ ERGODESIGN USIHC CINAHPA}

\section{Introdução}

O presente artigo faz um paralelo significativo e histórico dos temas que envolvem o desenvolvimento de produtos para pessoas com necessidades específicas, no caso andadores para idosos. Aborda temas como o design de produto, aspectos da mobilidade reduzida, ergonomia, a tecnologia assistiva, os andadores, o material de fabricação (alumínio) e as novas pesquisas na área, com o objetivo de registrar a importância destes conhecimentos para o desenvolvimento de novos produtos. Afirmando a importância dos dados ergonômicos com a finalidade de minimizar os riscos aos usuários.

O cenário populacional do Brasil tem apresentado um crescimento no número de idosos, e consequentemente uma crescente necessidade de dispositivos que propiciem o auxílio aos que possuem uma mobilidade reduzida. $\mathrm{O}$ envelhecimento acarreta um declínio na saúde das pessoas, com a senilidade o enfraquecimento dos membros inferiores ocorre em maior frequência, levando a uma maior propensão a quedas, lesões e demais fatores que tiram a independência e autonomia dessa faixa etária.

Um dispositivo de auxílio à mobilidade reduzida que atua como complemento na marcha humana e está presente dentre os pertencentes da Tecnologia Assistiva é o andador. O seu uso é benéfico aos idosos, pois permite uma maior estabilidade no caminhar e o cumprimento de seus afazeres diários, contribuindo para um bem-estar de independência e satisfação. No entanto os andadores são equipamentos que necessitam de uma maior atenção no que se refere aos cuidados com o emprego do tipo de material, como também dos aspectos ergonômicos e a presença da função estética para a melhor aceitação do uso perante a terceira idade.

Portanto, o presente objetiva propiciar um estudo de fatores que norteiam os andadores para idosos, que são fundamentais para sua projeção e para o bom uso do seu utilizador. $16^{\circ}$ Ergodesign - Congresso Internacional de Ergonomia e Usabilidade de Interfaces Humano Tecnológica: Produto, Informações Ambientes Construídos e Transporte

$16^{\circ}$ USIHC - Congresso Internacional de Ergonomia e Usabilidade de Interfaces Humano Computador

CINAHPA | 2017 - Congresso Internacional de Ambientes Hipermídia para Aprendizagem.

\section{Revisão Bibliográfica}

Para traçar uma linha de conexão no desenvolvimento do projeto, foram apurados tópicos essenciais para um embasamento adequado a fim de relacionar os parâmetros que norteiam a construção de um andador destinado aos idosos.

\subsection{Design de Produto}

Ao mencionar o conceito de design, de acordo com [BÜRDEK, 2010] o "Oxford Dictionary" foi o primeiro veículo que trouxe o vocábulo "design" em 1588. Segundo [LÖBACH, 2001], o termo pode ser traduzido como configuração e/ou projeto; e sua origem advém do termo alemão Gestaltung. Entende-se como sendo Design Industrial o produto que é passível de fabricação industrial e busca satisfazer as necessidades dos usuários, possuindo relação direta com questões físicas e psíquicas que auxiliam na qualidade de vida dos mesmos.

Essa preocupação de projetar objetos com uma finalidade aprimorada é vista desde os tempos ancestrais, que evidenciava a qualidade dos produtos com formas, a fim de trazer praticidade e funcionalidade ao cotidiano. Essa base do funcionalismo, conforme [BÜRDEK, 2010], muito presente no século $\mathrm{XX}$, foi lançado por Vitruvius, que pregava três características essenciais para a configuração dos objetos, sendo elas: a solidez (firmitas), a utilidade (utilitas) e a beleza (venutas).

Remetemos a [LÖBACH, 2001], quando assemelhamos seu pensamento ao de Vitruvius, $o$ primeiro referido defende que um bom produto de design deva atender a três funções básicas: a prática, a estética e a simbólica. De modo a gerar interação entre o uso do produto para com o usuário (Figura 1):

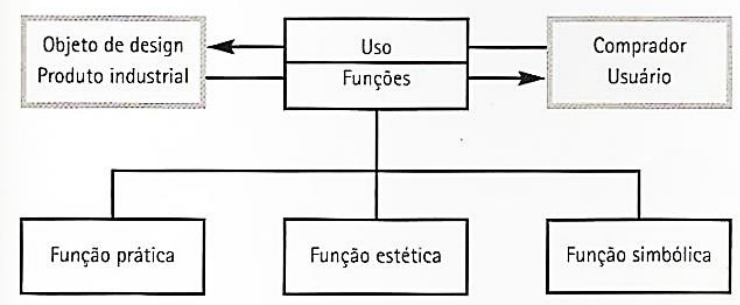

Figura 1 - Classificação das funções de um produto. Fonte: LÖBACH, (2001).
Realização:
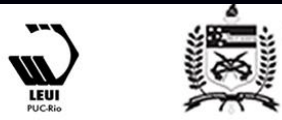


\section{$16^{\circ}$ \\ ERGODESIGN USIHC CINAHPA}

$16^{\circ}$ Ergodesign - Congresso Internacional de Ergonomia e Usabilidade de Interfaces Humano Tecnológica: Produto, Informações Ambientes Construídos e Transporte

$16^{\circ}$ USIHC - Congresso Internacional de Ergonomia e Usabilidade de Interfaces Humano Computador

CINAHPA | 2017 - Congresso Internacional de Ambientes Hipermídia para Aprendizagem.
[LÖBACH, 2001] apresenta que a função prática de um produto é levar satisfação ao usuário por sua necessidade física, ou seja, a relação do comportamento do homem para com o objeto, e assim qualificar sua interação e cumprir com os objetivos pela qual the foram destinados. Em seguida, descreve a função estética como sendo motivadora no processo de escolha positiva ou negativa do produto no primeiro contato para com o consumidor. Uma vez que atua na aplicação da percepção das cores, acabamentos, formas e demais aspectos que farão o objeto receber destaque no mercado, mediante os concorrentes e a necessidade de venda. Por fim, a função simbólica traz o poder de influência psicológica, social e espiritual de uso que um produto pode transmitir, pois atua como objeto de valor que é acrescido pelo comprador, seja por interação de status, por uma sensação que remete um toque familiar ou outras características que farão com que o consumo do produto seja viável ao que se define de simbologia à pessoa.

A relevância dessas funções em um projeto de design implica em um produto que atenderá a requisitos essenciais para o bom funcionamento $\mathrm{e}$ aceitação do usuário, podendo ser adquirido por uma questão de conforto prático, simbólico, estético ou a união desses três pontos que gerarão um produto de notável evidência no comércio de sua concorrência.

\subsection{Mobilidade Reduzida}

Conforme os dados analisados e sistematizados pela Organização Pan-americana de Saúde [OPAS, 2005, apud BOIANI et al., 2015], pode-se apontar que a população idosa brasileira vem apresentando altas taxas de crescimento nas últimas décadas. A senilidade cresce cada vez mais, e algumas alterações de índices demográficos corroboram tal afirmativa, como por exemplo: aumento da expectativa de vida e redução das taxas de fecundidade e mortalidade; que possibilita inferir em um cenário, onde a população idosa é cada vez mais crescente enquanto o número de nascimento de crianças é decrescente.

Em referência aos dados discriminados abaixo, o website G1, apresenta o perfil da população brasileira tomando como base estatística os resultados da Pesquisa Nacional por Amostra de Domicílios (PNAD) do Instituto Brasileiro de Geografia e Estatística (IBGE). O levantamento fora realizado no ano de 2013, com a participação de 362.555 pessoas espalhadas em 1.100 municípios brasileiros. [G1.GLOBO, 2014].

Verifica-se um aumento no grupo de idade de 40 a 59 anos, e também no de 60 anos ou mais, (Figura

2) em relação às demais faixas (que sofreram redução ou se mantiveram estáveis).

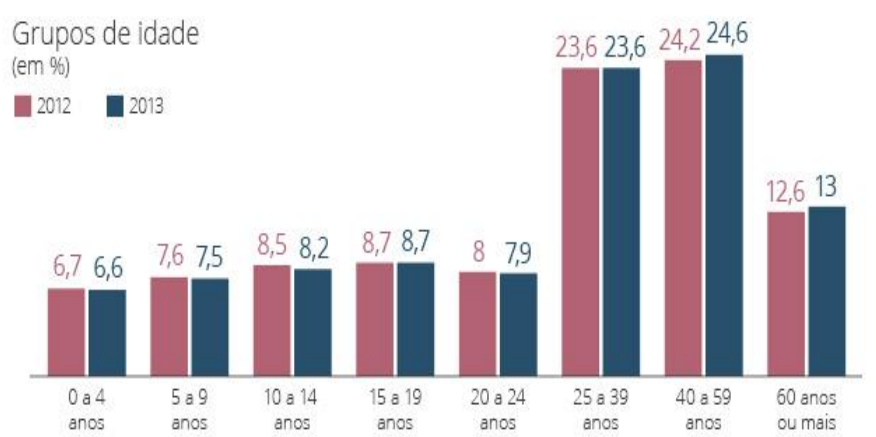

Figura 2 - Gráfico de Grupos de idade da população brasileira em 2013.

Fonte: G1.GLOBO, (2014).

As décadas anteriores a de 1960 mostrava uma população constituída, sobretudo por jovens. Porém com um cenário positivo em relação à longevidade da população, controle de natalidade e diminuição da mortalidade, se vê índices demográficos que apresentam um Brasil com crescente número da população idosa e diminuição no número de crianças. [OPAS, 2005, apud, BOIANI, et al., 2015].

Em um cenário onde a população idosa é crescente, e que, consequentemente necessita de dispositivos de auxílio à locomobilidade, [BOIANI et al., 2015] explicita que, por conta do processo de envelhecimento e dos problemas típicos como o aumento do risco de quedas, podemos evidenciar que a saúde do idoso é algo totalmente relevante. Esses dispositivos causam o crescimento no consumo de mercado por justamente facilitar a emancipação em realizar tarefas do cotidiano e a mobilidade pessoal do idoso.
Realização:

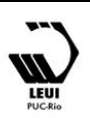




\section{$16^{\circ}$ \\ ERGODESIGN USIHC CINAHPA}

Concomitantemente, onde a locomobilidade do idoso é limitada (quando nos deparamos em questões de ordem pública, como por exemplo: cidades que não possuem suporte adequado de calçadas), a questão da independência e autonomia se evidencia e tem que ser repensada e ajustada, e é nesse ponto que se vê a necessidade dos dispositivos de auxílio à mobilidade reduzida. [BOIANI et al., 2015].

\subsection{Ergonomia}

O conceito de ergonomia foi trazido das civilizações antigas, que frequentemente buscavam melhorias em seus utensílios, ferramentas e instrumentos rotineiros, de modo a vitalizá-los por meio da aplicabilidade de formas proficientes sem a necessidade de requisitos de projeto, somente por análises e testes experimentais. [MORAES; MONT'ALVÃO, 2012] descreve que o termo ergonomia é utilizado pela primeira vez no dia 8 de julho de 1949 como conhecimento específico pelo psicólogo inglês K. F. Hywel Muffel, na Ergonomic Research Society que debatia as condições dos seres humanos em seus ambientes de trabalho, advindos da Revolução Industrial na Europa nos séculos XVIII e XIX.

[IIDA, 2005] evidencia algumas diretrizes do estudo da ergonomia e suas interações ressaltam a finalidade de um conjunto que propicia um ambiente de trabalho produtivo e eficiente proporcionando ao homem uma interação de conforto, satisfação e segurança. Essas diretrizes permeiam: o homem e suas características como idade, sexo, fatores físicos, psicológicos e fisiológicos. A máquina, que são todos os equipamentos que fazem contato direto ou indireto para com o homem. O ambiente que atua como condições na presença de ruídos, vibrações, luzes, temperatura e outros. E a informação responsável na tomada de decisões e o ato comunicacional.

Para estudar o homem é necessária à aplicação de medidas que sejam viáveis ao registro do públicoalvo, ou medidas utilizadas pela máquina, que em questão é o andador. Desse modo a Associação Brasileira de Normas Técnicas - [ABNT, 2015] disponibiliza um manual com a norma brasileira $16^{\circ}$ Ergodesign - Congresso Internacional de Ergonomia e Usabilidade de Interfaces Humano Tecnológica: Produto, Informações Ambientes Construídos e Transporte

$16^{\circ}$ USIHC - Congresso Internacional de Ergonomia e Usabilidade de Interfaces Humano Computador

CINAHPA | 2017 - Congresso Internacional de Ambientes Hipermídia para Aprendizagem.

ABNT NBR 9050, definindo padrões comumente usados na acessibilidade em edificações, mobiliário, espaços e equipamentos urbanos. Esse manual contempla padrões antropométricos do dispositivo andador, na qual expõe dimensões baseadas no percentil entre $5 \%$ a $95 \%$ da população brasileira, ou seja, a medida de mulheres de baixa estatura e homens de estatura elevada. (Figura 3):
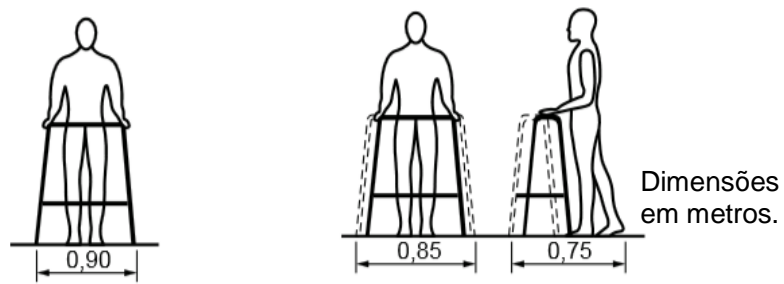

Andador com rodas Andador rígido - Vistas frontal e lateral

Figura 3 - Dimensões referenciais a pessoa com o dispositivo andador.

Fonte: ABNT - NBR 9050, (2015).

Essas medidas servirão de parâmetro para a estruturação do projeto do andador para que ocorra uma percepção de espaço adequado de locomoção dos usuários. Como embasamento de auxílio para fundamentar as dimensões e os conceitos que envolvem a antropometria do homem a obra de [IIDA, 2005] servirá como apoio para o presente estudo.

As medidas antropométricas são muito afetadas conforme as alterações corporais fisiológicas que ocorrem mediante o envelhecimento, de acordo com [WANDERLEY, 2015]. A massa corpórea após os 60 anos de idade sofre redução, levando a uma limitação de controle e até mesmo no peso dos órgãos. A população idosa sofre com alterações como a perca de líquido do corpo, que acaba por afetar a estrutura óssea e causando o achatamento do arco plantar. Essas modificações estruturais fazem com que a coluna vertebral sofra com um arqueamento, que, por conseguinte, alteram medidas de estatura, como cerca de um centímetro a cada dez anos e intensifica-se aos 70 anos.

[MASTROENI, et al., 2010] faz um estudo do munício de Joinville - SC sobre as medidas antropométricas dos idosos, e essa análise
Realização:

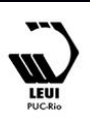




\section{$16^{\circ}$ \\ ERGODESIGN USIHC CINAHPA}

disponibiliza variáveis de acordo com os percentis apresentados nas (Tabelas 1) e (Tabela 2):

\begin{tabular}{|c|c|c|c|c|c|c|c|c|}
\hline \multirow{2}{*}{ Grupo etário } & \multirow[b]{2}{*}{$\mathbf{n}$} & \multicolumn{7}{|c|}{ Percentis } \\
\hline & & 5 & 10 & 25 & 50 & 75 & 90 & 95 \\
\hline \multicolumn{9}{|l|}{ Peso (kg) } \\
\hline Total & 87 & 50,94 & 54,40 & 63,35 & 68,70 & 77,30 & 85,28 & 93,18 \\
\hline $60-69$ & 53 & 52,97 & 57,91 & 63,75 & 70,00 & 76,05 & 84,27 & 93,06 \\
\hline $70-79$ & 27 & 43,64 & 49,69 & 61,55 & 68,00 & 78,70 & 91,96 & 96,77 \\
\hline$>80$ & 7 & 50,90 & 50,90 & 62,05 & 64,45 & 77,25 & 83,75 & 83,75 \\
\hline \multicolumn{9}{|l|}{ Estatura $(\mathrm{cm})$} \\
\hline Total & 87 & 153,70 & 155,12 & 161,40 & 167,45 & 171,05 & 174,13 & \\
\hline $60-69$ & 53 & 153,46 & 155,73 & 161,07 & 167,05 & 171,02 & 174,61 & 178,92 \\
\hline $70-79$ & 27 & 145,82 & 154,91 & 161,50 & 167,55 & 172,00 & 174,37 & 175,84 \\
\hline$>80$ & 7 & 153,50 & 153,50 & 158,50 & 162,60 & 170,00 & 172,05 & 172,05 \\
\hline \multicolumn{9}{|l|}{$\mathrm{IMC}\left(\mathrm{kg} / \mathrm{m}^{2}\right)$} \\
\hline Total & 87 & 19,46 & 20,82 & 23,60 & 25,40 & 27,30 & 29,92 & 32,98 \\
\hline $60-69$ & 53 & 19,84 & 21,98 & 23,60 & 25,40 & 27,30 & 30,42 & 33,57 \\
\hline $70-79$ & 27 & 16,64 & 19,62 & 21,70 & 24,80 & 27,50 & 30,42 & 33,22 \\
\hline$>80$ & 7 & 19,30 & 19,30 & 21,10 & 25,70 & 26,30 & 29,00 & 29,00 \\
\hline
\end{tabular}

Tabela 1 - Variáveis antropométricas de homens idosos do município de Joinville - SC.

Fonte: MASTROENI, (2010).

\begin{tabular}{|c|c|c|c|c|c|c|c|c|}
\hline \multirow{2}{*}{ Grupo etário } & \multirow{2}{*}{$\mathrm{n}$} & \multicolumn{7}{|c|}{ Percentis } \\
\hline & & 5 & 10 & 25 & 50 & 75 & 90 & 95 \\
\hline \multicolumn{9}{|l|}{ Peso (kg) } \\
\hline Total & 130 & 47,60 & 51,31 & 56,22 & 65,62 & 74,91 & 86,96 & 97,77 \\
\hline $60-69$ & 81 & 47,68 & 49,72 & 58,42 & 67,40 & 75,67 & 87,62 & 99,70 \\
\hline $70-79$ & 43 & 46,44 & 51,34 & 55,85 & 64,10 & 72,80 & 84,81 & 94,26 \\
\hline$>80$ & 6 & 53,95 & 53,95 & 54,43 & 56,57 & 69,26 & 103,80 & 103,80 \\
\hline \multirow{2}{*}{\multicolumn{9}{|c|}{ Estatura $(\mathrm{cm})$}} \\
\hline Total & 130 & 142,33 & 145,56 & 149,86 & 154,92 & 160,00 & & 166,54 \\
\hline $60-69$ & 81 & 143,95 & 145,92 & 150,02 & 155,45 & 160,35 & 163,99 & 165,74 \\
\hline $70-79$ & 43 & 142,24 & 145,82 & 149,50 & 153,50 & 159,00 & 165,99 & 170,68 \\
\hline \multirow{2}{*}{\multicolumn{9}{|c|}{ IMC $\left(\mathrm{kg} / \mathrm{m}^{2}\right)$}} \\
\hline & & & & & & & & \\
\hline Total & 130 & 20,45 & 22,50 & 24,20 & 27,35 & 29,82 & 34,87 & 37,63 \\
\hline $60-69$ & 81 & 20,00 & 21,84 & 24,20 & 28,00 & 31,05 & 34,74 & 37,82 \\
\hline $70-79$ & 43 & 20,26 & 22,74 & 25,00 & 26,40 & 28,90 & 34,06 & 37,58 \\
\hline$>80$ & 6 & 23,20 & 23,20 & 23,87 & 26,05 & 30,60 & 37,50 & 37,50 \\
\hline
\end{tabular}

Tabela 2 - Variáveis antropométricas de mulheres idosas do município de Joinville - SC.

Fonte: MASTROENI, (2010).

O fornecimento desses dados possibilita que o dispositivo seja projetado baseando-se nas medidas específicas dos idosos, dessa maneira podemos afirmar que o produto desenvolvido levando essas considerações é adequado ao público objeto de estudo.

\subsection{Tecnologia Assistiva}

[SARTORETTO; BERSCH, 2017] relatam que em 1988 foi criado nos Estados Unidos o termo Assistive Technology (Tecnologia Assistiva) e incorporado na legislação com o desígnio de garantir os direitos das pessoas com deficiência e direcionar verbas para equipamentos e suporte digno a esse setor. É uma área do conhecimento que busca a independência e inclusão de pessoas com deficiência por meio de metodologias, ferramentas, recursos e demais requisitos que dão total aparato para uma melhor qualidade de vida.

A Tecnologia Assistiva é aparada por materiais de classificação que permite ao indivíduo um $16^{\circ}$ Ergodesign - Congresso Internacional de Ergonomia e Usabilidade de Interfaces Humano Tecnológica: Produto, Informações Ambientes Construídos e Transporte

$16^{\circ}$ USIHC - Congresso Internacional de Ergonomia e Usabilidade de Interfaces Humano Computador

CINAHPA | 2017 - Congresso Internacional de Ambientes Hipermídia para Aprendizagem. tratamento exclusivo de suas dificuldades, o que é fundamental, pois propicia estudar a fundo cada caso e assim conquistar satisfação e autonomia ao deficiente. Dentre as 11 categorias da Tecnologia Assistiva, encontra-se a de auxílios de mobilidade, que engloba os veículos de auxílio à locomobilidade pessoal, como bases móveis, andadores, cadeiras de rodas motorizadas e manuais, entre outros. [SARTORETTO; BERSCH, 2017].

$\mathrm{O}$ andador é considerado um dispositivo que complementa a marcha do indivíduo com mobilidade reduzida rumo a uma maior autonomia, auxiliando-o em realizar suas atividades rotineiras e contribuindo psicologicamente de modo a valorizar sua independência e utilidade mediante a sociedade. No entanto é possível notar a preocupação da ausência do design nessa área da Tecnologia Assistiva, [SARTORETTO; BERSCH, 2017] relatam a necessidade de uma melhoria geral da qualidade dos aparatos de auxílio, que tem como função imprimir usabilidade e aprazimento de uso ao idoso.

É substancial a ocorrência de incentivos aos estudos na área de Tecnologia Assistiva e a demanda de dispositivos auxiliadores, de acordo com [SARTORETTO; BERSCH, 2017], visando a revitalização dos projetos, com o objetivo das pessoas com deficiência ou mobilidade reduzida poderem receber benefícios de locomoção e inclusão em ambientes da sociedade, que vão desde a relação familiar até o relacionamento interpessoal com os amigos, trabalho e outros, com o propósito de garantir qualidade de vida e satisfação pessoal.

\subsection{Andador}

Não foram encontrados registros da datação do surgimento do andador para adultos, mas para fundamentar os princípios do aparecimento do objeto e sua função ao ser humano foram anexadas bibliografias referentes à origem do andador infantil.

De acordo com [OLD AND INTERESTING, 2008], nos séculos XIV e XV os andadores infantis
Realização:
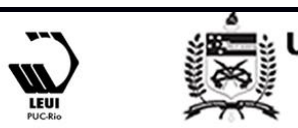


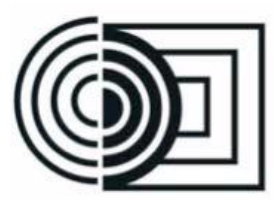

apareceram em obras de cunho artístico e traziam o ideal da evolução da marcha da criança. No século XVII o propósito do andador além de auxiliar na marcha, era da manutenção na posição vertical do corpo, o que poderia contribuir fisicamente e moralmente na formação da criança.

Os registros encontrados aparecem como bordados da Igreja Católica no século XIV (Figura 4), onde se destina a prática de caminhar com andadores feitos em madeira. Outro registro, como pintura do século XIX (Figura 5) se assemelha com cestas e não permite grande mobilidade, apenas por uma conveniência dos adultos para criação. [OLD AND INTERESTING, 2008].

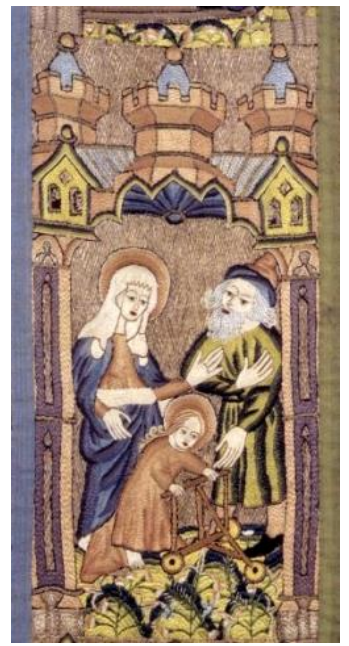

Figura 4 - Bordado da Igreja Católica no século XIV em referência ao andador infantil.

Fonte: OLD AND INTERESTING, (2008).

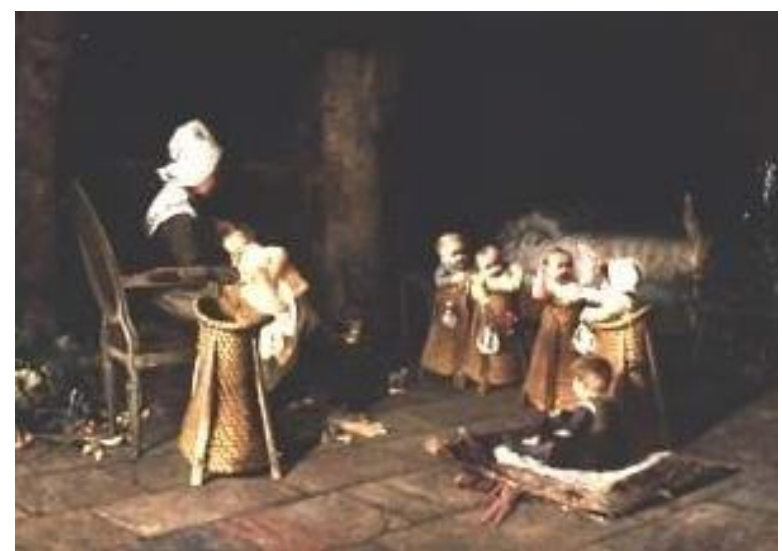

Figura 5 - Cesta francesa em uma pintura do século XIX. Fonte: OLD AND INTERESTING, (2008). $16^{\circ}$ Ergodesign - Congresso Internacional de Ergonomia e Usabilidade de Interfaces Humano Tecnológica: Produto, Informações Ambientes Construídos e Transporte

$16^{\circ}$ USIHC - Congresso Internacional de Ergonomia e Usabilidade de Interfaces Humano Computador

CINAHPA | 2017 - Congresso Internacional de Ambientes Hipermídia para Aprendizagem.
A Nova Inglaterra já era portadora dos conhecimentos sobre o dispositivo desde o século XVII. No entanto, o nome andador é registrado pela primeira vez na América no século XIX. [OLD AND INTERESTING, 2008] aponta que na década de 1870, nos Estados Unidos, muitos reivindicavam a necessidade de patente do objeto declarando adquirir melhorias a este e indicando ser a combinação de andador/cadeira.

[BOIANI, et al., 2015] orienta que o andador é um dispositivo eficaz à postura, porque possui um contato seguro e amplo com o solo, transmitindo estabilidade ao seu utilizador. Os modelos mais comumente encontrados no mercado são os de pés fixos; com rodízio nos pés anteriores; com assento e com colete de sustentação, mencionados pela Tecnologia Assistiva em seu Catálogo Nacional de Produtos, conforme a (Figura 6):
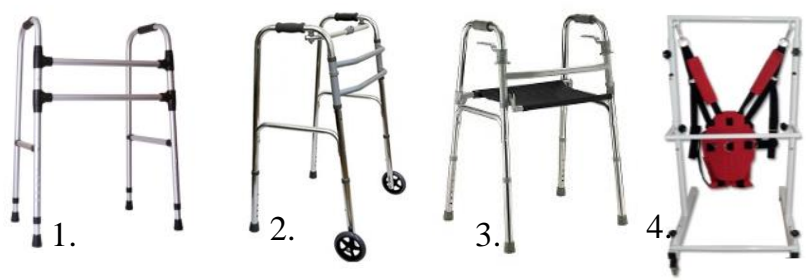

Figura 6 - Modelos de andadores: 1. Pés fixos; 2. Rodízios nos pés anteriores; 3 . Com assento; 4 . Com colete de sustentação.

Fonte: Elaborado pela autora.

O idoso encontra desvantagens quando utiliza o andador devido aos obstáculos e pisos irregulares, calçadas inadequadas ou a nulidade de uma estética que auxilie na aceitação do produto. Essa ausência estética é aspecto que motiva a desistência de uso do aparelho, e esse desuso causa danos psicológicos e físicos ao idoso por rejeitar o objeto ao não se sentir satisfeito, incentivando-o ao sedentarismo, comprometendo a independência e a evolução motora. $\mathrm{O}$ dispositivo deve ser prescrito por profissionais que conheçam a necessidade de cada indivíduo para amenizar o risco de quedas e lesões. É indispensável o incentivo e investimentos econômicos para que pesquisas possam ser realizadas, e, assim, colocar em pauta o idoso como centro de atenção. [BOIANI, et al., 2015] relata que as disciplinas dos cursos de Design, das
Realização:
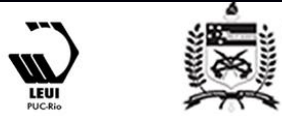


\section{$16^{\circ}$ \\ ERGODESIGN USIHC CINAHPA}

Engenharias e demais cursos podem trazer novos estudos de geração de produtos a idosos e a Tecnologia Assistiva, baseados em conceitos ergonômicos e formais visando a aceitação dos que necessitam do uso de dispositivos.

\subsection{Alumínio}

[COSTA, 2016] expõe que o papel do alumínio se inicia em 1807, quando foram relatados os primeiros registros sobre sua descoberta e processo de produção, realizado por Sir. Humphry Davy. O alumínio é um material que apresenta características de leveza, condutividade elétrica, de moldagem simples, etc.

Apresentando como determinante comercial do alumínio, tem-se a bauxita (material rochoso formado principalmente por óxido de alumínio, e compostos como sílica, óxido de titânio, óxido de ferro, apresentando uma coloração avermelhada). A Terra possui em sua crosta cerca de $7 \%$ de alumínio, ficando atrás apenas do composto oxigênio e silício, mostrado na (Figura 7) por [COSTA, 2016].

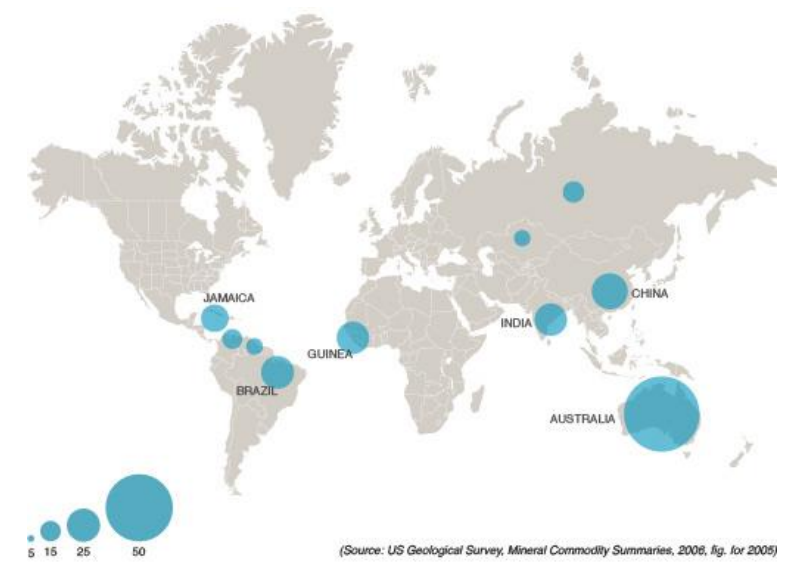

Figura 7 - Mineração de bauxita em milhões de toneladas métricas por ano.

Fonte: CASTRO, (2016).

O alumínio apresenta uma versatilidade realmente valiosa, principalmente quando pensada a partir de sua reutilização através do processo de reciclagem, apresentando uma taxa de utilização no mercado de alumínio por volta de $55 \%$, implicando na redução do preço final ao utilizador, por consumir $16^{\circ}$ Ergodesign - Congresso Internacional de Ergonomia e Usabilidade de Interfaces Humano Tecnológica: Produto, Informações Ambientes Construídos e Transporte

$16^{\circ}$ USIHC - Congresso Internacional de Ergonomia e Usabilidade de Interfaces Humano Computador

CINAHPA | 2017 - Congresso Internacional de Ambientes Hipermídia para Aprendizagem.

apenas 5\% da energia inicial de seu processo, tornando-se vantajoso em questão de custo e poupança de energia. [COSTA, 2016].

Assim, se vê que o alumínio é um material extremamente viável para a projeção do andador, devido a sua facilidade de moldagem e possibilidade de reciclagem, o que implica na não perca de sua estrutura caso ela tenha concluído o seu ciclo de vida, além das características de resistência, leveza e sutileza no acabamento, visando um projeto com estética aprazível e seguro ao idoso.

\subsection{Novas Pesquisas na Área}

A nova maneira de se pensar os andadores para adultos é tema de preocupação por parte de alguns designers, que esboçaram e realizaram estudos para fins de projeto com o intuito de oferecer maior praticidade aliado a uma estética mais agradável do produto. Além disso, vê se a necessidade de voltar um olhar mais acurado em relação a esta temática cada vez mais importante na sociedade atual.

O conceito de andador (Figura 8) do designer de produto Fernando Vieira Sobczak.

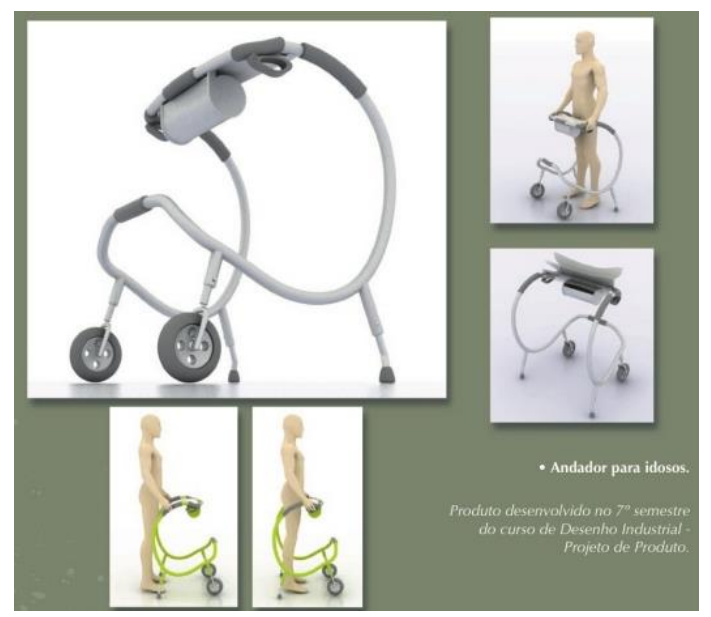

Figura 8 - Conceito de andador. Fonte: SOBCZAK, (2009).

O MP Walker, criado pelo designer Andres Sanchez, permite não só a conveniência de ir de
Realização:
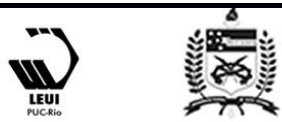


\section{$16^{\circ}$ \\ ERGODESIGN USIHC CINAHPA}

$16^{\circ}$ Ergodesign - Congresso Internacional de Ergonomia e Usabilidade de Interfaces Humano Tecnológica: Produto, Informações Ambientes Construídos e Transporte

$16^{\circ}$ USIHC - Congresso Internacional de Ergonomia e Usabilidade de Interfaces Humano Computador

CINAHPA | 2017 - Congresso Internacional de Ambientes Hipermídia para Aprendizagem. um lugar para outro com segurança, como oferece estética inovadora e diversos modos de dobra, auxiliando na questão de armazenamento e mobilidade (Figura 9).

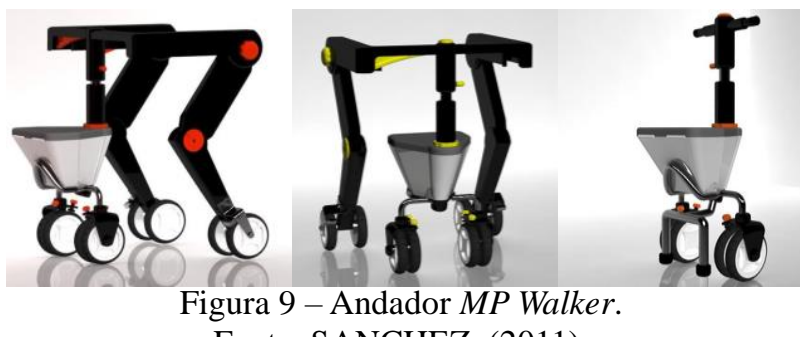

Fonte: SANCHEZ, (2011).

Philip James Davis apresentou como projeto no site do Behance um andador para idosos, marcado por uma estética elegante e simples, mediante aos disponíveis no mercado-alvo. (Figura 10). Possui um sistema de alavancas que permite ao usuário: apoio e a posição sentada, além da grande área para armazenamento e preocupações ergonômicas.

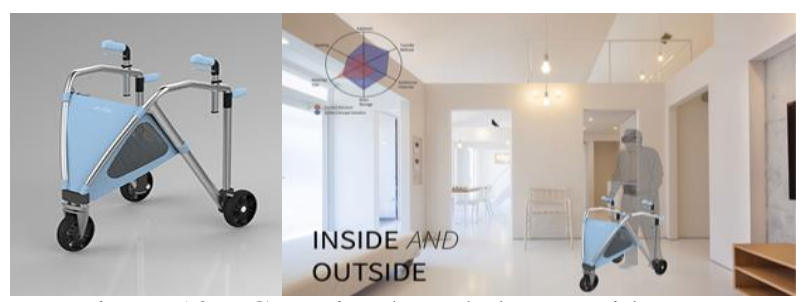

Figura 10 - Conceito de andador para idosos. Fonte: DAVIS, (2014).

Daniel Molloy, estudante de design da Universidade de Monash, projetou uma ferramenta de auxílio à mobilidade dos idosos, focando em segurança. Molloy traz como objetivo a função de subir e descer escadas, com o intuito de diminuir os riscos de quedas. O Boomer (Figura 11) combina qualidade e uma forma moderna agradável.

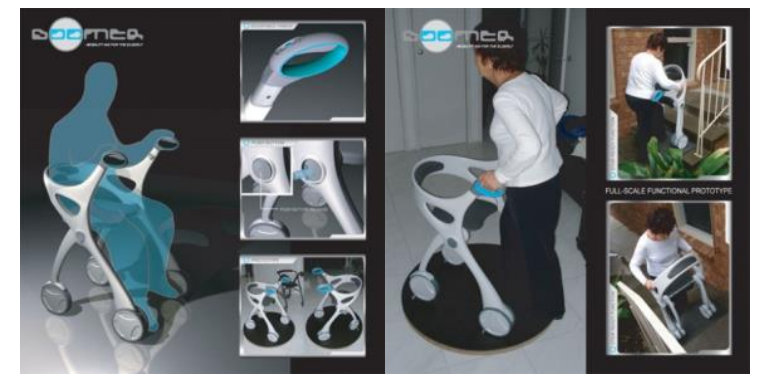

Figura 11 - Andador Boomer.

Fonte: MOLLOY, (2016).
Como verificação dos conceitos propostos para andadores, pode-se notar a presença de traços orgânicos e arredondados no emprego estético para o desenvolvimento projetual. É notável que as seleções empreguem o uso de formas que não isolam os princípios do objeto já conhecido, criando dessa maneira uma afeição perante o utilizador, mas aplicando critérios díspares dos encontrados no mercado consumidor, propiciando a aceitação e o contentamento de uso.

\section{Discussões}

Foram analisados temas que incluem informações históricas e conceituais ligadas diretamente para com o dispositivo andador, que embasam um conhecimento auxiliador para os produtos com a finalidade de apoio a pessoas com mobilidade reduzida.

Pode-se destacar que o andador é um produto que requer a análise de diversos pontos que complementam o seu funcionamento e até mesmo sua atuação de venda no mercado consumidor. $\mathrm{O}$ estudo aponta que esse tipo de dispositivo requer uma minuciosa atenção para suas questões ergonômicas, pois implica em dados antropométricos dos usuários em estudo e dimensões dos ambientes, pela qual o produto será inserido. Ao relatar o ambiente pode-se analisar que os idosos encontram grandes dificuldades para se locomoverem devido à má estrutura das calçadas e vias de acesso, que deveriam contemplar um parâmetro igualitário e um suporte adequado para o cumprimento de suas funções.

O fator ambiente é um dos motivos para que haja o abandono do uso do andador. Outro aspecto que contribui para a desistência é a falta de uma estética mais agradável e que disponha ao idoso a satisfação de usá-lo, permitindo a criação de uma ligação simbólica com o produto. É substancial que a forma do andador alinhado a sua estética possua total completude com as funções práticas do objeto, com a ergonomia, com as normas que categorizam a Tecnologia Assistiva e outras abordagens necessárias para a projeção. A análise das novas pesquisas na área é fundamental para complementar e direcionar padrões visuais ao
Realização:
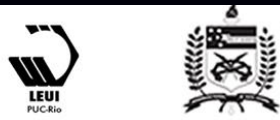


\section{$16^{\circ}$ \\ ERGODESIGN USIHC CINAHPA}

$16^{\circ}$ Ergodesign - Congresso Internacional de Ergonomia e Usabilidade de Interfaces Humano Tecnológica: Produto, Informações Ambientes Construídos e Transporte

$16^{\circ}$ USIHC - Congresso Internacional de Ergonomia e Usabilidade de Interfaces Humano Computador

CINAHPA | 2017 - Congresso Internacional de Ambientes Hipermídia para Aprendizagem. projeto.

Assim sendo, a necessidade analisada norteia a presença de estudos que demonstrem a participação do Design em aparelhos relacionados com a área da saúde e a aplicação de dispositivos mais bem planejados, com a finalidade de estimular o utente ao seu uso adequado, permitindo a satisfação psicológica e motora.

\section{Notas Conclusivas}

Com os avanços dos índices sociais, principalmente no que concernem estatísticas positivas em relação à qualidade de vida da população brasileira idosa (aumento da expectativa de vida), faz-se necessário, cada dia mais, a realização de estudos voltados para os cuidados pessoais dessa faixa etária, onde a elaboração de aparatos para indivíduos com mobilidade reduzida é imprescindível para a saúde dos mesmos.

Contribuir com a vitalidade e o bem-estar dos indivíduos, em especial os idosos, é papel preponderante à setores da ciência e das áreas que podem dar sua salutar cooperação, e em especial o Design, que tem como propósito a criação e projeção de produtos para o usufruto humano que vise a qualidade, a durabilidade, a estética e formas concernentes a suas funções. Essa aplicabilidade deve se tornar frequente quando envolvida à área da Tecnologia Assistiva, que sofre com a carência de uma revitalização e uma melhoria geral de qualidade aos suportes que englobam as categorias de auxílio, direcionando na geração da usabilidade e contento ao utilizador.

A geração de andadores e dispositivos que auxiliam pessoas com mobilidade reduzida deve implicar em um aprofundamento no ramo da ergonomia, pois é um estudo primordial à saúde do usuário que necessita de equipamentos produzidos para um uso adequado, contribuindo para a diminuição de fadigas, estresse, carga excessiva dos membros superiores e inferiores; e outros aspectos que tornarão a vida do indivíduo mais autônoma e de qualidade. É imprescindível a presença da ergonomia em novos projetos, já que demonstra a interação entre o ser humano e a máquina com o intuito de empregar usabilidade e até empenhar papel de inovação à grade de aprendizagem e tecnologia.

$\mathrm{O}$ andador é um produto que transmite ao utilizador noção de segurança, equilíbrio e maior autonomia para realizar suas atividades diárias, desde que a indicação seja feita por especialistas à idosos que necessitam desse aparato a fim de não propiciar o uso incorreto e a não geração de quedas, lesões ou danos psicológicos. Como analisado, o Design deve se preocupar com princípios que circundam o desenvolvimento dos produtos, e no caso do andador é basilar que além da ergonomia, haja o emprego do material adequado para sua fabricação, com o objetivo de dar resistência, leveza e longevidade ao ciclo de vida do produto. Outro fator que é gerador do desuso da ferramenta de apoio é a ausência estética nos projetos, que seriam sanadas com o emprego de formas que traduzem praticidade e auxilie em uma percepção satisfatória de uso, sem abandonar o conceito já formado pelo público-alvo para reconhecimento, ou seja, que ocorra a mescla de uma função estética e prática aliada à simbologia funcional de identificação do objeto.

O estudo dimensiona com relevância para a sociedade a valorização de produtos mais bem planejados que visem a melhoria na vida das pessoas. É importante que empresas voltadas para a fabricação desses equipamentos possam investir em ideias e projetos que revitalizem como um todo a oferta de seus produtos ao mercado, estimulando a concorrência e acima de tudo disponibilizando ao consumidor itens de qualidade, de competência e satisfação.

Conclui-se, portanto, que o andador deva resguardar em sua projeção um cuidado para com as questões ergonômicas, estéticas e de fabricação por um material que atenda a parâmetros sustentáveis, de resistência e durabilidade, ou seja, adequados para cumprir as funções pelas quais foram designadas, e como analisado no desenvolvimento do trabalho o alumínio é o componente que preenche esses requisitos. É um subsídio para independência ao idoso e transmite segurança de locomoção e benefícios à saúde física
Realização:

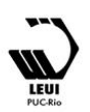




\section{$16^{\circ}$ \\ ERGODESIGN USIHC CINAHPA}

e psicológica; e é de suma importância que ocorra incentivos e estudos voltados à essa área para que haja ainda mais suporte de qualidade e novos conceitos do produto, favorecendo os atores que exercem relações com esse empreendimento.

\section{Referências}

ABNT. Acessibilidade a edificações, mobiliário, espaços e equipamentos urbanos. ABNT NBR 9050. Rio de Janeiro, 2015.

BOIANI, J. A. M.; FERREIRA, A. C. M.; BOTURA JUNIOR, G.; PASCHOARELLI, L. C.; MEDOLA, F. O. Prescrição e uso de andadores para idosos: Uma demanda para o Design Ergonômico. In: Anais do $15^{\circ}$ Ergodesign \& Usihc [=Blucher Design Proceedings, vol. 2, num. 1]. São Paulo: Blucher, 2015.

BÜRDEK, B. E. Design: História, Teoria e Prática do Design de Produtos. 2.ed. São Paulo: Blucher, 2010.

COSTA, B. F. da. Alumínio como pele de alçado: três casos de estudo. Lisboa, 2016. Disponível em: < http://repositorio.ulusiada.pt/handle/11067/2515>. Acesso em: 30 ago. 2016.

DAVIS, P. J. Behance.net. 2014. Major Degree Project - Elderly Walking Aid. Disponível em: $<$ https://www.behance.net/gallery/16946639/MAJ OR-DEGREE-PROJECT-Elderly-Walking-Aid>. Acesso em: 03 set. 2016.

G1. GLOBO. Idosos já são 13\% da população e país tem menos crianças, diz PNAD: números do brasil. São Paulo, 2014. Disponível em: < http:/g1.globo.com/economia/noticia/2014/09/idosos-jasao-13-da-populacao-e-pais-tem-menos-criancas-dizpnad.html>. Gráfico em: < http:/g1.globo.com/economia/pnad-resultados-2013/>. Acesso em: 08 set. 2016.

IIDA, Itiro. Ergonomia: Projeto e Produção. $2^{\mathrm{a}}$ ed. São Paulo: Editora Blucher, 2005.

LÖBACH, B. Design Industrial: Bases para a configuração dos produtos industriais. 1.ed. São $16^{\circ}$ Ergodesign - Congresso Internacional de Ergonomia e Usabilidade de Interfaces Humano Tecnológica: Produto, Informações Ambientes Construídos e Transporte

$16^{\circ}$ USIHC - Congresso Internacional de Ergonomia e Usabilidade de Interfaces Humano Computador

CINAHPA | 2017 - Congresso Internacional de Ambientes Hipermídia para Aprendizagem.

Paulo: Blucher, 2001.

MASTROENI, M. F.; SILVA MASTROENI, S. S. de B.; ERZINGER, G. S.; MARUCCI, M. de F. N. Antropometria de idosos residentes no município de Joinville-SC, Brasil. Rio de Janeiro: Revista Brasileira de Geriatria e Gerontologia (RBGG), 2010.

MOLLOY, D. Tuvie.com. 2016. Boomer: A User Friendly Walking Aid For Eldery People. Disponível em: <http://www.tuvie.com/boomer-auser-friendly-walking-aid-for-eldery-people/>. Acesso em: 03 set. 2016.

MORAES, A. D.; MONT'ALVÃO, C.

Ergonomia: Conceitos e Aplicações. 4. ed. Rio de Janeiro: Editora 2AB, 2012.

OLD AND INTERESTING. Baby Walkers \& Standing Stools. 2008. Disponível em:

$<\mathrm{http} / / /$ www.oldandinteresting.com/baby-walkershistory.aspx>. Acesso em: 05 set. 2016.

SANCHEZ, A. Behance.Net. 2011. Mp Walker. Disponível em: <

https://www.behance.net/gallery/1305537/MPWalker-for-Elderly-people >. Acesso Em: 03 Set. 2016.

SARTORETTO, M. L.; BERSCH, R. Assistiva: Tecnologia e educação. 2017. Disponível em: <http://www.assistiva.com.br/>. Acesso em: 28 fev. 2017.

SOBCZAK, F. V. coroflot.com. 2009. Portfolio. Disponível em:

<http://www.coroflot.com/fernandovieira/portfolio 1>. Acesso em: 03 set. 2016.

WANDERLEY, E. O Envelhecimento e as Alterações Corporais. Unicamp. Campinas, 2015. Disponível em: < https://ligadegeriatriaunicamp.wordpress.com/2015 /12/15/o-envelhecimento-e-as-alteracoescorporais/>. Acesso em: 02 maio 2017.
Realização:
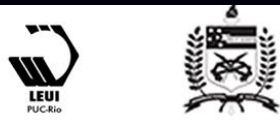